\title{
Study of the Adsorption of Methylene Blue and Tartrazine in Aqueous Solution by Local Materials of Cameroonian Origin
}

\author{
Djakba Raphaël ${ }^{1,}$, , Harouna Massaï ${ }^{1,2}$, Wangmene Bagamla ${ }^{1}$, Bouba Talami ${ }^{1}$ \\ ${ }^{1}$ Department of Chemistry, Faculty of Science, University of Maroua, Maroua, Cameroon \\ ${ }^{2}$ Department of Chemistry, Chemical Engineering and Mineral Industries, University of Ngaoundéré, Ngaoundéré, Cameroon

\section{Email address:} \\ djakbakon@gmail.com (D. Raphaël), harounamassai@yahoo.fr (H. Massaï), wangmenebagamla@yahoo.com (W. Bagamla), \\ isaactalami@gmail.com (B. Talami) \\ ${ }^{*}$ Corresponding author
}

\section{To cite this article:}

Djakba Raphaël, Harouna Massaï, Wangmene Bagamla, Bouba Talami. Study of the Adsorption of Methylene Blue and Tartrazine in Aqueous Solution by Local Materials of Cameroonian Origin. American Journal of Physical Chemistry. Vol. 9, No. 3, 2020 , pp. 45-51. doi: 10.11648/j.ajpc.20200903.11

Received: July 12, 2020; Accepted: July 27, 2020; Published: August 17, 2020

\begin{abstract}
The present work concerns the study of the adsorption of methylene blue (MB) and tartrazine (TAR) in aqueous solution by the raw clay (AB) and bridged clay (AP) of "Boboyo". Studies show that the adsorption of these two dyes on both adsorbents is very fast. The adsorption equilibrium time is 25 minutes for $\mathrm{AB}$ for both adsorbates and 15 and 30 minutes for TAR and BM on AP, respectively. The maximum adsorbed amounts of BM are of the order of $4.49 \mathrm{mg} / \mathrm{g}$ on $\mathrm{AB}$ and $4.39 \mathrm{mg} / \mathrm{g}$ on AP. They are of the order of $2.43 \mathrm{mg} / \mathrm{g}$ on AB and $2.64 \mathrm{mg} / \mathrm{g}$ on AP for TAR. The experiments show that the adsorbed quantity of these two dyes decreases with the increase of the mass of the adsorbents, is maximum at $\mathrm{pH}=3$ and increases with the increase of the initial concentration of the two dyes. The modeling of the adsorption kinetics reveals a conformity to the pseudo-second order model for the two dyes studied on adsorbent disputes. Experimental results are better described with the Freundlich isothermal model. The thermodynamic parameters showed that the adsorption of the two dyes is favorable and endothermic.
\end{abstract}

Keywords: Crude Clay, Bridged Clay, Adsorption, Methylene Blue and Tartrazine

\section{Introduction}

The greatest danger to the environment and the degradation of the ecosystem is pollution. Whether accidental or voluntary, pollution is the result of the misuse of organic and/or mineral compounds. The textile industry is an important source of liquid effluents containing pollutants mainly in dyes. The latter have many applications in different fields such as dyeing and printing on fiber and fabrics of all kinds, coloring foodstuffs, dyes for medicinal and cosmetic use [1]. For the most part, these dyes are hardly biodegradable compounds, they are recognized, toxic or harmful to humans and animals. For example, tartrazine develops a number of adverse reactions in some individuals such as pruritus, edema, urticaria, asthma and rhinitis [2]. Various conventional methods have been used to remove organic pollutants from water. The most used methods are made by chemical, physicochemical or biological methods such as coagulation, flocculation, precipitation and membrane filtration, and adsorption, which is the most effective treatment method for removing dyes [3-6]. In this study, we opted for the adsorption process, which is considered one of the most widely used treatment techniques for removing organic compounds and metal ions in general from water. For a long time, the most requested material for this process is activated carbon. Certainly the costs of treatment with this medium are interesting; nevertheless, several disadvantages limit its frequent use. Indeed, saturation and regeneration of coal, its selective adsorption poses a problem for industrialists who are in constant search of cheap adsorbents [7]. Many materials have been tried for the removal of dyes. They include algae, industrial waste: red 
mud, agricultural by-products, seafood waste: chitin [8-9]. The objective of this work is to study the adsorption of two dyes, methylene blue (MB) and tartrazine (TAR) on local materials, in this case raw clay (AB) and bridged clay (AP) Boboyo (Far North, Cameroon). A study of adsorption isotherms and kinetic is carried out to elucidate the adsorption mechanism of these two dyes on local materials.

\section{Methodology}

\subsection{Obtaining Raw Clay (AB)}

The clay used as adsorbents in this study is extracted in earthen mud from the Boboyo deposit in the Far North Region of Cameroon, Mayo-Kani Department, Kaélé District. After grinding and sieving, the Stock method was used to obtain the clay fraction $(<2 \mu \mathrm{m})$. The clay fractions obtained were treated successively with dilute sulfuric acid and hydrochloric acid and then washed extensively with distilled water. So we got our raw clay.

\subsection{Obtaining Bridged Clay (AP)}

$40 \mathrm{~g}$ of crude clay is treated three times with a solution of sodium chloride with magnetic stirring for 24 hours. After washing several times with distilled water, we obtained the sodium clay which was dried in an oven at $105^{\circ} \mathrm{C}$ for 2 hours. The bridging solution was prepared by titrating a $0.1 \mathrm{M}$ aluminum sulfate with $0.1 \mathrm{M}$ sodium hydroxide solution contained in a separating funnel with a batch flow. During the titration, the homogenization of the medium is carried out by a magnetic stirrer in order to avoid the local supercalinted solutions, which can trigger the formation of the precipitate of the metal hydroxide. The aluminum hydroxide solution obtained is kept for 48 hours in the dark. The bridging of the clay by metal polycations is carried out according to a succession of fundamental operations which are cation exchange followed by heat treatment. $10 \mathrm{~g}$ of sodium clay is introduced into a reactor containing $200 \mathrm{~mL}$ of distilled water which we have homogenized for 1 hour. In the following the clay suspension is metered drop by drop with the bridging solution with magnetic stirring. At the end of the dosing, we left the clays in contact with the metal polycations for 48 hours in the dark. After several washes with distilled water until the removal of chloride ions, the bridged clay was dried in an oven at $105^{\circ} \mathrm{C}$ for 24 hours, then calcined at $400^{\circ} \mathrm{C}$ for 3 hours.

\subsection{Adsorption Tests of BM and TAR on AB and AP}

In each experiment, the adsorbent $(\mathrm{AB}$ or $\mathrm{AP})$ is contacted with a solution of distilled water in which the dye (BM or TAR) has been dissolved.

\subsubsection{Contact Time}

We treated volumes of $20 \mathrm{~mL}$ of identical solutions of concentration of about $24 \mathrm{mg} / \mathrm{L}$ of the dye (BM or TAR) with a mass of $0.1 \mathrm{~g}$ of adsorbent ( $\mathrm{AB}$ or $\mathrm{AP}$ ), the mixture is agitated with using a magnetic stirrer, the samples are collected at well-defined time intervals ranging from 5 to
40 minutes, the whole is filtered. The residual concentration of the dye was measured by absorption spectrophotometry. The quantity $\mathrm{q}_{\mathrm{t}}$ of the adsorbed dye is given by the relation:

$$
\mathrm{q}_{\mathrm{t}}=\frac{\left(\mathrm{C}_{0}-\mathrm{C}_{\mathrm{r}}\right) \mathrm{V}}{\mathrm{m}}
$$

With,

$\mathrm{q}_{\mathrm{t}}$ : Amount of adsorbed dye per gram of adsorbent $(\mathrm{mg} / \mathrm{g})$;

$\mathrm{C}_{0}$ : Initial concentration of the dye $(\mathrm{mg} / \mathrm{L})$;

$\mathrm{C}_{\mathrm{r}}$ : Residual concentration at equilibrium $(\mathrm{mg} / \mathrm{L})$;

$\mathrm{V}$ : Volume of the solution (L);

$\mathrm{m}$ : Mass of the adsorbent $(\mathrm{g})$.

\subsubsection{Influence of Some parameters on Adsorption}

Influence of $\mathrm{pH}$

The same procedure is carried out at room temperature, adjusting the initial $\mathrm{pH}$ of the dye solutions using the $\mathrm{NaOH}$ $(1 \mathrm{~N})$ and $\mathrm{HCl}(1 \mathrm{~N})$ solutions for the different $\mathrm{pH}$ values studied (3; $5 ; 7 ; 9 ; 11)$.

Influence of the initial quantity of clay

The effect of the initial mass of clay was studied at the $\mathrm{pH}$ of maximum adsorption of the solution, at room temperature and at a concentration of $24 \mathrm{mg} / \mathrm{L}$. The masses of clay chosen vary between 0.1 and $0.5 \mathrm{~g}$.

Influence of the initial concentration of the solution

The effect of the initial dye concentration was studied by stirring, $20 \mathrm{~mL}$ of dye solutions, at the maximum adsorption $\mathrm{pH}$ of the solution, mixed with $0.1 \mathrm{~g}$ of clay and at room temperature. The concentrations used range from 1 to $24 \mathrm{mg} / \mathrm{L}$.

\subsubsection{Modeling of Adsorption Kinetics}

Adsorption kinetics were modeled using kinetic pseudoorder surface reaction models 1 and 2, the Elovich kinetic model and the kinetic intraparticle diffusion model.

Model of pseudo first order kinetics (Lagergren model)

Lagergren proposed a kinetic model of pseudo first order expressed by the following relation [10]:

$$
\frac{\mathrm{dq}}{\mathrm{dt}}=\mathrm{k}_{1}\left(\mathrm{q}_{\mathrm{e}}-\mathrm{q}_{\mathrm{t}}\right)
$$

With,

$\mathrm{k}_{1}$ : Speed constant for kinetics of pseudo first order $\left(\min ^{-1}\right)$;

$\mathrm{q}_{\mathrm{t}}$ : Adsorption capacity at time $\mathrm{t}(\mathrm{mg} / \mathrm{g})$;

$\mathrm{q}_{\mathrm{e}}$ : Adsorption capacity at equilibrium (mg/g).

The integration of equation (2) gives:

$$
\ln \left(\mathrm{q}_{\mathrm{e}}-\mathrm{q}_{\mathrm{t}}\right)=\ln \mathrm{q}_{\mathrm{e}}-\mathrm{k}_{1} \mathrm{t}
$$

Model of kinetics pseudo second order It is represented by the following formula:

$$
\frac{d q_{t}}{d t}=k_{2}\left(q_{e}-q_{t}\right)^{2}
$$

With,

$\mathrm{k}_{2}$ : Speed constant for second-order kinetics (g/mg. min);

$\mathrm{q}_{\mathrm{t}}$ : Adsorption capacity at time $\mathrm{t}(\mathrm{mg} / \mathrm{g})$;

$\mathrm{q}_{\mathrm{e}}$ : Adsorption capacity at equilibrium (mg/g). 
The integration of equation (4) gives:

$$
\frac{\mathrm{t}}{\mathrm{q}_{\mathrm{t}}}=\frac{1}{\mathrm{k}_{2} \mathrm{q}_{\mathrm{e}}^{2}}+\frac{1}{\mathrm{q}_{\mathrm{e}}} \mathrm{t}
$$

By representing the function $\frac{t}{q_{t}}=f(t)$, the quantity of equilibrium adsorbed ions $\mathrm{q}_{\mathrm{e}}$ and the pseudo-second order velocity constant $\mathrm{k}_{2}$ can be determined from the slope and the ordinate at origin.

Intra particle scattering model

It is represented by the following equation:

$$
\mathrm{q}_{\mathrm{t}}=\mathrm{K}_{\mathrm{int}} \sqrt{\mathrm{t}}+\mathrm{C}
$$

With,

$\mathrm{q}_{\mathrm{t}}$ : Relative amount of the molecule adsorbed at time $\mathrm{t}$;

$\mathrm{K}_{\text {int }}$ : Intra particle particle constant;

$\mathrm{C}$ : Value of the thickness of the boundary layer.

The curve $q_{t}=f(\sqrt{t})$ makes it possible to obtain a line of slope $\mathrm{K}_{\mathrm{int}}$ and an ordinate at the origin $\mathrm{C}$.

Elovich model

This model is described by the equation:

$$
\frac{\mathrm{dq}}{\mathrm{dt}}=\alpha \mathrm{e}^{-\beta \mathrm{q}_{\mathrm{t}}}
$$

By simplifying the Elovich equation under the initial conditions: $\alpha \beta>\mathrm{t}, \mathrm{q}_{\mathrm{t}}=0$ to $\mathrm{t}=0$ and $\mathrm{q}_{\mathrm{t}}=\mathrm{q}_{\mathrm{t}}$ to $\mathrm{t}=$ $t$, the equation can be written as follows:

$$
\mathrm{q}_{\mathrm{t}}=\frac{1}{\beta} \ln (\alpha \beta)+\frac{1}{\beta} \ln \mathrm{t}
$$

With,

$\alpha$ : Initial adsorption rate $(\mathrm{mg} / \mathrm{g} . \mathrm{min})$;

$\beta$ : Adsorption constant (g/mg).

$\alpha$ and $\beta$ can be obtained by plotting the curve $\mathrm{q}_{\mathrm{t}}=\mathrm{f}(\ln \mathrm{t})$ which is a line of slope $\frac{1}{\beta}$ and the ordinate at the origin $\frac{1}{\beta} \ln (\alpha \beta)$.

\subsubsection{Modeling of Adsorption Isotherms}

Langmuir Model

The Langmuir equation is expressed by:

$$
\mathrm{q}_{\mathrm{e}}=\frac{\mathrm{K}_{L} \cdot \mathrm{q}_{\mathrm{m}} \cdot \mathrm{C}_{\mathrm{e}}}{1+\mathrm{K}_{L} \mathrm{C}_{\mathrm{e}}}
$$

or in the linear form:

$$
\frac{\mathrm{C}_{\mathrm{e}}}{\mathrm{q}_{\mathrm{e}}}=\frac{1}{\mathrm{~K}_{L} \cdot \mathrm{q}_{\mathrm{m}}}+\frac{\mathrm{C}_{\mathrm{e}}}{\mathrm{q}_{\mathrm{m}}}
$$

With,

$\mathrm{C}_{\mathrm{e}}$ : Equilibrium concentration $(\mathrm{mg} / \mathrm{L})$;

$\mathrm{q}_{\mathrm{e}}$ : Quantity adsorbed at equilibrium $(\mathrm{mg} / \mathrm{g})$;

$\mathrm{q}_{\mathrm{m}}$ : Maximum adsorption capacity of the monolayer (mg/g);

$\mathrm{K}_{\mathrm{L}}$ : Langmuir parameter.

The representation of $\frac{\mathrm{C}_{\mathrm{e}}}{\mathrm{q}_{\mathrm{e}}}$ vs $\mathrm{C}_{\mathrm{e}}$ makes it possible to determine the coefficients $\mathrm{q}_{\mathrm{m}}$ and $\mathrm{K}_{\mathrm{L}}$ for the adsorption of the ions of the solution.

Freundlich model
The Freundlich equation is written:

$$
\mathrm{q}_{\mathrm{e}}=\mathrm{K}_{\mathrm{F}} \mathrm{C}_{\mathrm{e}}^{1 / \mathrm{n}}
$$

With,

$\mathrm{q}_{\mathrm{e}}$ : Quantity adsorbed per gram of solid (mg/g);

$\mathrm{C}_{\mathrm{e}}$ : Equilibrium concentration $(\mathrm{mg} / \mathrm{L})$;

$\mathrm{K}_{\mathrm{F}}$ and $n$ : Freundlich parameters, characteristics of the solution and the adsorbent, determined experimentally.

The equation can be linearized as follows:

$$
\ln q_{e}=\ln K_{F}+\left(\frac{1}{n}\right) \cdot \ln C_{e}
$$

High values of $\mathrm{K}_{\mathrm{F}}$ and $\mathrm{n}$ indicate strong adsorption of solutes.

Temkin model

The equation of this isotherm is given by:

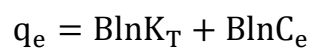

With,

$\mathrm{B}=\mathrm{RT} / \mathrm{b}_{\mathrm{T}}$ : Constant related to adsorption energy;

$\mathrm{R}$ : Constant of perfect gases $(8.314 \mathrm{~J} / \mathrm{mol})$;

$\mathrm{T}$ : Temperature $(\mathrm{K})$;

$\mathrm{b}_{\mathrm{T}}$ : Adsorption potential $(\mathrm{J} / \mathrm{mol})$;

$\mathrm{K}_{\mathrm{T}}$ : Constant equilibrium bond $(\mathrm{L} / \mathrm{g})$.

\section{Results and Interpretation}

\subsection{Influence of Contact Time on the Elimination of BM and $T A R$}

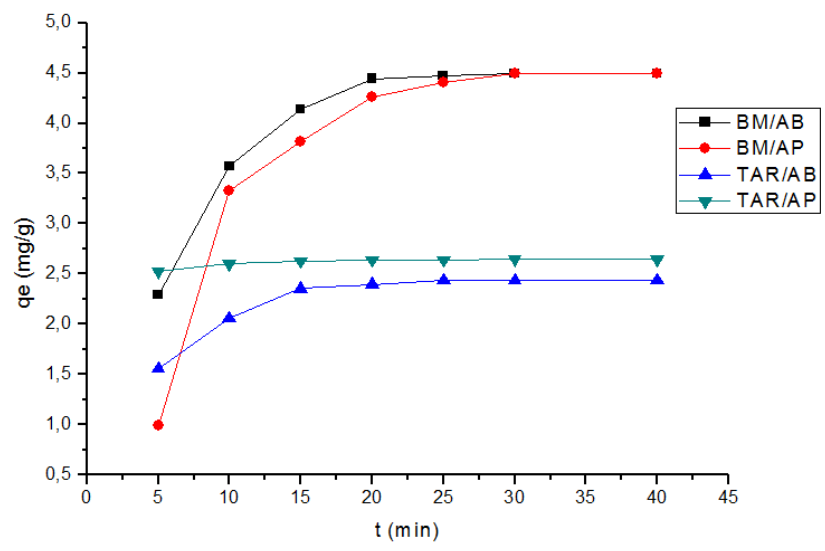

Figure 1. Adsorption kinetics of $B M$ and TAR on $A B$ and $A P$.

Figure 1 shows the amount of $\mathrm{BM}$ and $\mathrm{AR}$ adsorbed on $\mathrm{AB}$ and AP as a function of time. The results of Figure 1 show that the adsorption of BM and TAR has two distinct steps regardless of the adsorbent used. The first step is fast and corresponds to the external mass transfer. It is due to the fact that at the beginning of the adsorption the sites available are much more important. The second step is slow and is related to the diffusion phenomenon. It is explained by the fact that almost all the active sites of the adsorbents are occupied by the molecules of the dyes. The latter obstruct the pores thus slowing the rate of adsorption, so we observe the bearings. We consider that the adsorption of BM and TAR on the 
various adsorbents $(\mathrm{AB}$ and $\mathrm{AP})$ is a fast process since we obtained an equilibrium time of 25 minutes for $\mathrm{AB}$ and 15 and 30 minutes respectively for TAR and BM on AP. The maximum adsorbed amounts of BM are of the order of $4.49 \mathrm{mg} / \mathrm{g}$ on $\mathrm{AB}$ and $4.39 \mathrm{mg} / \mathrm{g}$ on AP. They are of the order of $2.43 \mathrm{mg} / \mathrm{g}$ on $\mathrm{AB}$ and $2.64 \mathrm{mg} / \mathrm{g}$ on $\mathrm{AP}$ for TAR.

\subsection{Effect of Adsorbent Mass on BM and TAR Removal}

In order to estimate the mass of $\mathrm{AB}$ and $\mathrm{AP}$ to be added to the solution of pollutants for maximum adsorption, we conducted our experiments using $20 \mathrm{~mL}$ of BM and TAR solution at $24 \mathrm{mg} / \mathrm{L}$ at which different masses of adsorbents have been added. The results are shown in Figure 2. It is apparent from Figure 2 that the adsorbed amount decreases with the mass of the adsorbent regardless of the adsorbent used. This decrease in adsorbed quantity is explained by the fact that:

When the mass of adsorbent is low, the dye molecules can easily access the adsorption sites. The increase in the mass of the adsorbent makes it possible to increase the number of adsorption sites, but the molecules of the dyes have difficulty approaching these sites because of the bulk [11].

A large amount of adsorbent mass creates agglomerations of the particles, resulting in a reduction in the total adsorption surface thus decreasing the amount of adsorbate per unit mass of the adsorbent.

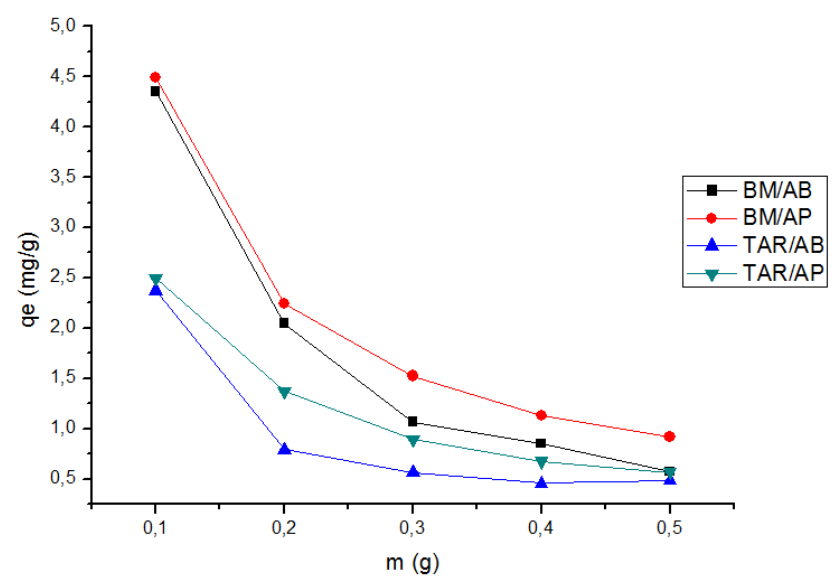

Figure 2. Influence of the mass of adsorbent on the adsorption of the two dyes.

\subsection{Effect of pH on BM and TAR Elimination}

The adsorption of BM and TAR by AB and AP was studied for different $\mathrm{pH}$, under the following experimental conditions: $\mathrm{C}_{0}=24 \mathrm{mg} / \mathrm{L}, \mathrm{m}=0.1 \mathrm{~g}$, and $\mathrm{T}=25^{\circ} \mathrm{C}$. The results of this study are shown in Figure 3. The results obtained with BM show that the amount adsorbed is high in an acid medium. It is due to the fact that in acidic medium, the number of positively charged sites decreases because it can have the mesomere effect in the BM molecules. Similar results were obtained by Chaheb when adsorbed BM on raw touggourt clay [12]. In the case of TAR, the results show that the adsorbed quantity is maximal at $\mathrm{pH}=3$. In an acid medium, the positive charge dominates the surface of the clay. Thus, an electrostatic attraction exists between the positive charges of the surface of the clay and the negative charges of TAR. Similar results were observed by Mezenner et al. when they studied the adsorption of a mixture of Biorecalcitrant compounds in aqueous media [13]. Similarly, Akar and Uysal found that an acidic $\mathrm{pH}$ would increase the adsorption capacity of anionic dyes [14].

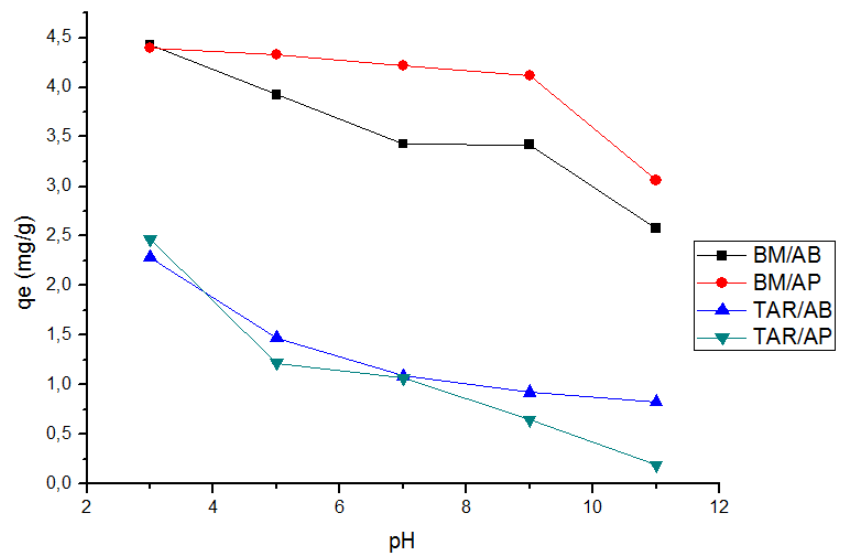

Figure 3. Effect of $p H$ on the adsorption of BM and TAR.

\subsection{Effect of Initial Concentration on MB and TAR Elimination}

The adsorption of BM and TAR is studied by increasing the initial concentration of the dyes under the following experimental conditions: $\mathrm{m}=0.1 \mathrm{~g}$, ambient temperature, and $\mathrm{pH}$ of the solution. The results are shown in Figure 4. We find that the adsorbed quantity increases with the increase of the initial concentration of the two dyes with the different adsorbents used. This is explained by the fact that, the higher the initial dye concentration increases, the more the number of dye molecules increases in the medium, and the steric hindrance decreases at the different adsorption sites. According to Chaheb, the adsorption capacity depends on the number of vacant sites on the surfaces of the adsorbents [12]. We also notice that the $\mathrm{BM}$ is much more adsorbed by our adsorbents than the TAR. We can say that our two adsorbents have a lot more affinity for BM than TAR.

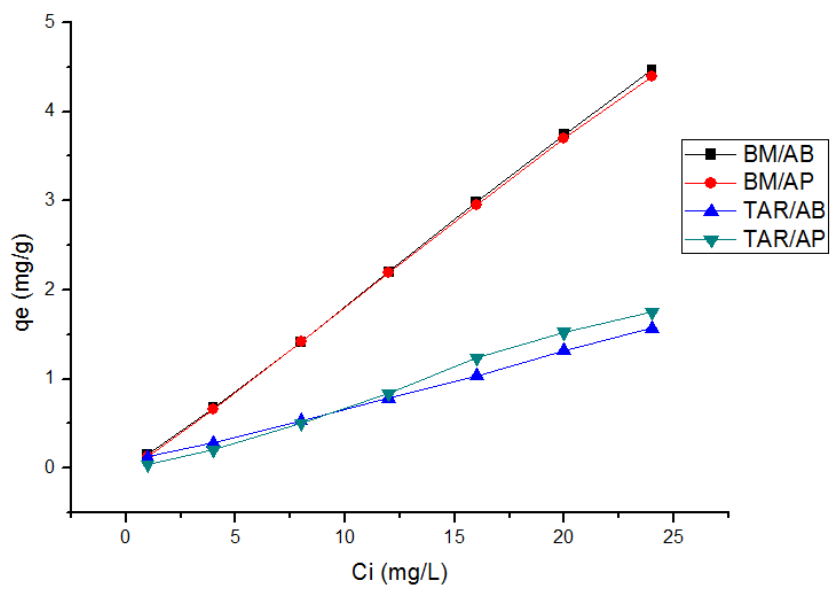

Figure 4. Effect of initial concentration on the adsorption of BM and TAR. 


\subsection{BM and TAR Adsorption Isotherms on $A B$ and $A P$}

The experimental results obtained are given in Figures 5 to 8 , in the form of a curve $\mathrm{q}_{\mathrm{e}} \mathrm{vs}_{\mathrm{e}}$, under the following conditions: $\mathrm{m}=0.1 \mathrm{~g}$, ambient temperature, and $\mathrm{pH}$ of the solution. The adsorption isotherms of $\mathrm{BM}$ on $\mathrm{AB}$ and $\mathrm{AP}$, and of TAR on AP are of type S called "sigmoid" according to the classification of Limousin et al. [15]. This type of isotherm reflects a cooperative adsorption that is to say the adsorbed molecules promote the subsequent adsorption of other molecules. This is due to the molecules that attract by Van Der Waals forces, and cluster in islands in which they pile up against each other, the adsorption-adsorbate interaction is stronger than that between adsorbent and adsorbate [16]. The adsorption isotherm of the TAR on $A B$ is of type $C$ called "constant partition". Linearity shows that the number of free sites remains constant during adsorption. This means that sites are created during adsorption. This implies that TAR molecules have altered AB's texture by opening pores that had not previously been opened [15].

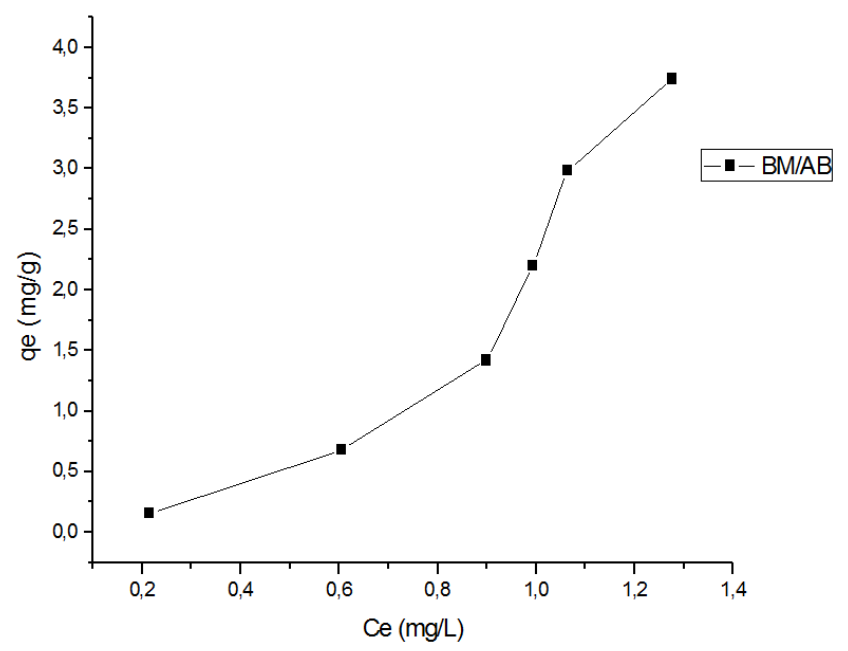

Figure 5. $B M$ adsorption isotherm on $A B$.

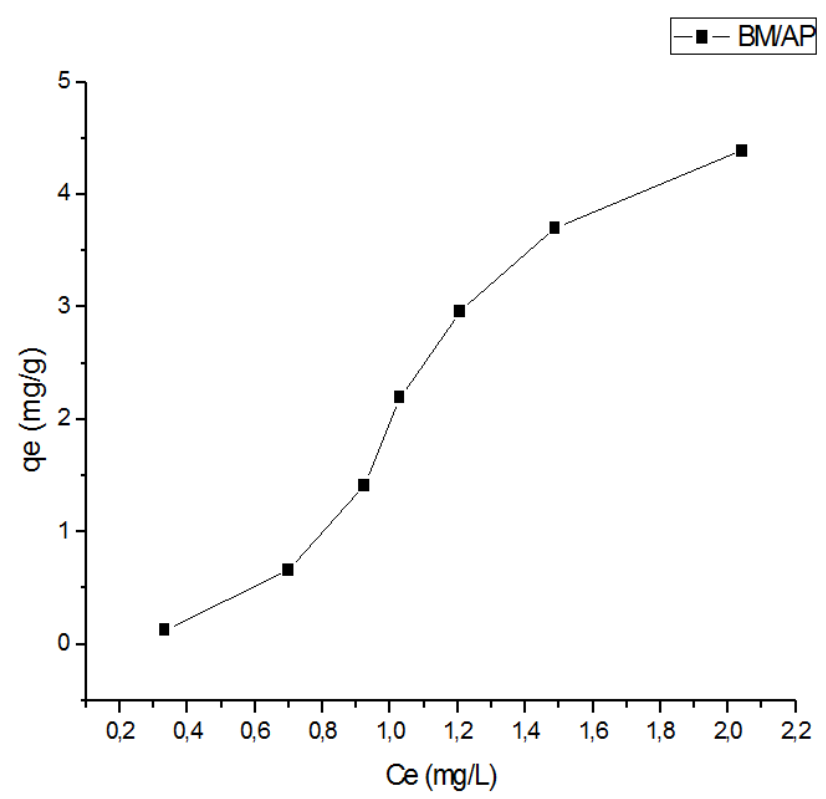

Figure 6. BM adsorption isotherm on AP.

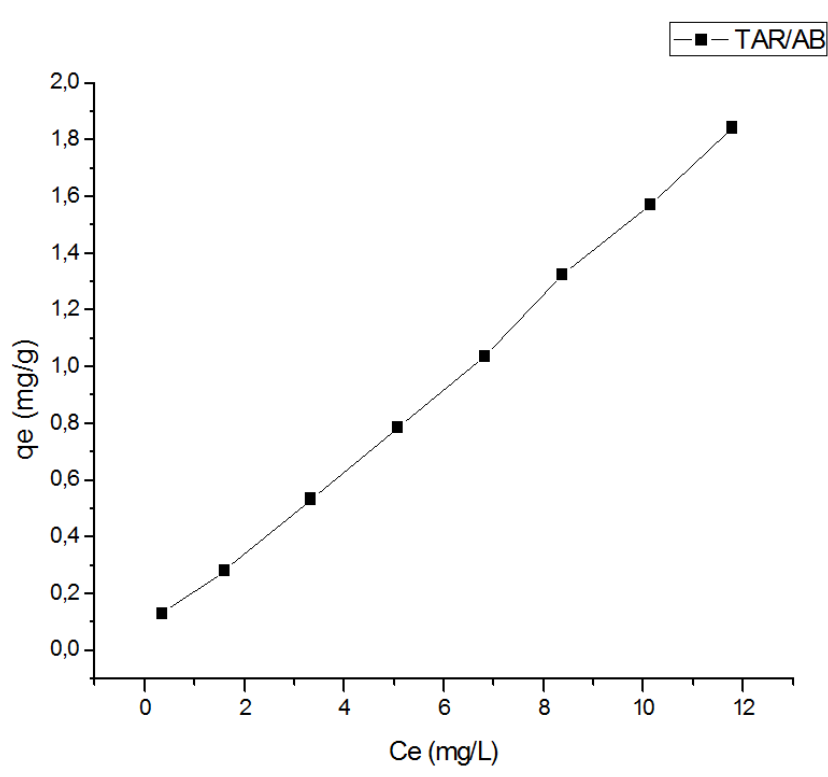

Figure 7. Adsorption isotherm of TAR on $A B$.

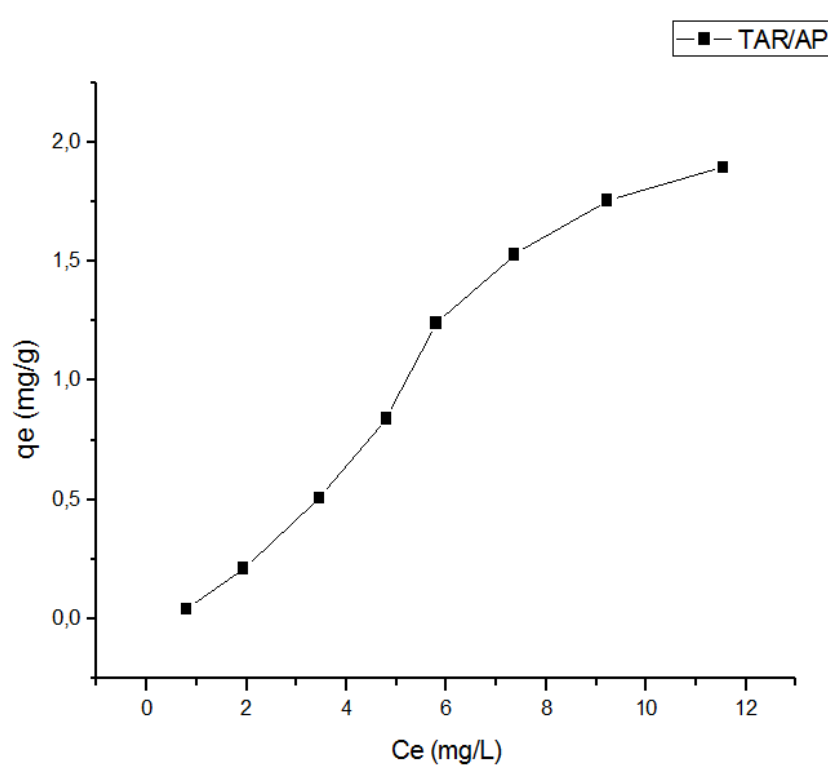

Figure 8. Adsorption isotherm of TAR on AP.

\subsection{Modeling the Adsorption Kinetics of BM and TAR on $A B$ and $A P$}

The adsorption rate constants of $\mathrm{BM}$ and TAR on $\mathrm{AB}$ and AP for pseudo-first order, pseudo-second order, intraparticular diffusion and Elovich are determined graphically. The rate constants for the four models were calculated from the lines obtained. Table 1 shows the different rate and diffusion constants, as well as the adsorbed quantities calculated for each model. From the results obtained shown in Table 1, the experimental results of BM adsorption on both cannot be described by any of the four models studied. On the other hand we note that pseudo firstorder and pseudo-second-order models are the most reliable for determining the order of adsorption kinetics of TAR by $\mathrm{AB}$ and $\mathrm{AP}$ with a correlation coefficient exceeding $96 \%$, because the values of the maximum equilibrium quantity 
calculated by these two are very close to those determined experimentally. The pseudo-second-order rate constants are larger compared to pseudo-first-order rate constants, which implies that the fixation of the TAR molecules on $\mathrm{AB}$ and $\mathrm{AP}$ is slower at the beginning of adsorption on the first types. Adsorption sites and, with time and more quickly, the solute molecules bind to the second types of sites [17].

Table 1. Different constants of velocities, diffusion and adsorbed quantities calculated deduced from the kinetic models.

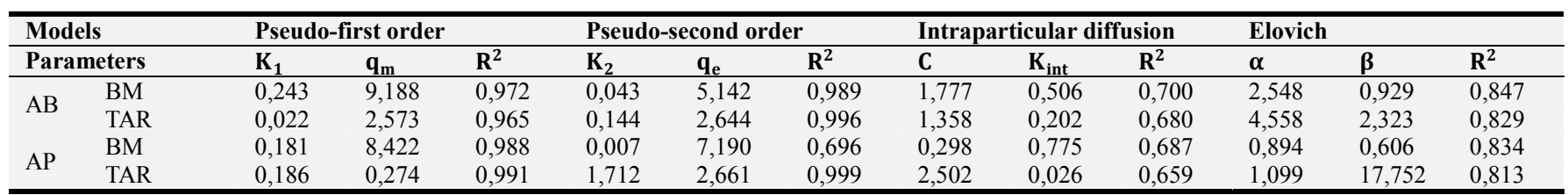

\subsection{Modeling of Adsorption Isotherms of BM and TAR on $A B$ and $A P$}

In order to determine the mechanism of the adsorption of $\mathrm{BM}$ and $\mathrm{TAR}$ on $\mathrm{AB}$ and $\mathrm{AP}$, we reproduced the experimental data by comparing them to the isothermal models of Langmuir, Freundlich and Temkin. The parameters for these adsorption models were calculated by regression using the linear form of the isothermal equations. The parameters and the correlation coefficient $\left(\mathrm{R}^{2}\right)$ are summarized in Table 2 . Table 2 presents for the Langmuir model, the thermodynamic parameter $\left(\Delta \mathrm{G}^{\circ}\right)$ at the temperature of $25^{\circ} \mathrm{C}$. The negative values of $\Delta \mathrm{G}^{\circ}$ for the two dyes indicate the spontaneous and thermodynamically favorable nature of the adsorption [18].
This value of $\Delta G^{\circ}$ is often used to indicate that the adsorption process is favorable and confirms the affinity of $\mathrm{AB}$ and AP for BM and TAR [19-20]. The essential characteristics of the Langmuir isotherm can be expressed by the separation factor or equilibrium parameter, $\mathrm{R}_{\mathrm{L}}$ which is used to predict whether an adsorption system is favorable or unfavorable. In our case, $R_{L}$ is less than 1 , so we can say that the adsorption is favorable. Table 2 shows that the Freundlich adsorption isotherm can describe the adsorption of $\mathrm{BM}$ and TAR on $\mathrm{AB}$ and AP. Correlation coefficients greater than $95 \%$ are observed. The low values of $K_{F}$ show a low adsorption capacity of $\mathrm{AB}$ and AP. $\Delta \mathrm{G}^{\circ}$ from Temkin is positive. This confirms that the adsorption of the two dyes by $\mathrm{AB}$ and $\mathrm{AP}$ is endothermic.

Table 2. Isotherm constants calculated for the adsorption of BM and TAR by AB and AP.

\begin{tabular}{|c|c|c|c|c|c|c|c|c|c|c|c|c|c|c|}
\hline \multirow{2}{*}{\multicolumn{2}{|c|}{$\begin{array}{l}\text { Models } \\
\text { Parameters }\end{array}$}} & \multicolumn{5}{|c|}{ Langmuir } & \multicolumn{3}{|c|}{ Freundlich } & \multicolumn{5}{|c|}{ Temkin } \\
\hline & & $\mathrm{K}_{\mathrm{L}}$ & $\mathbf{q}_{\mathrm{m}}$ & $\Delta \mathbf{G}^{\circ}$ & $\mathbf{R}_{\mathbf{L}}$ & $\mathbf{R}^{2}$ & $1 / n$ & $\mathbf{K}_{\mathbf{F}}$ & $\mathbf{R}^{2}$ & B & $\mathbf{b}_{\mathrm{T}}$ & $\mathbf{K}_{\mathbf{T}}$ & $\Delta \mathbf{Q}$ & $\mathbf{R}^{2}$ \\
\hline $\mathrm{AB}$ & $\mathrm{BM}$ & 0,55 & 1,35 & $-11,428$ & 0,07 & 0,76 & 1,74 & 2,08 & 0,97 & 2,08 & 1188 & 3,54 & 5,34 & 0,72 \\
\hline \multirow{2}{*}{ AP } & $\mathrm{BM}$ & 0,51 & 0,98 & $-11,616$ & 0,07 & 0,45 & 2,06 & 1,54 & 0,95 & 2,54 & 974,2 & 2,45 & 4,37 & 0,86 \\
\hline & TAR & 0,07 & 1,10 & $-16,538$ & 0,37 & 0,32 & 1,49 & 0,07 & 0,97 & 0,75 & 3264 & 0,87 & 8,63 & 0,87 \\
\hline
\end{tabular}

\section{Conclusion}

The objective of our work was to study the adsorption of BM and TAR by AB and AP of "Boboyo". The results obtained show that the maximum amount of BM adsorption is of the order of $4.49 \mathrm{mg} / \mathrm{g}$ on $\mathrm{AB}$ and $4.39 \mathrm{mg} / \mathrm{g}$ on AP. They are of the order of $2.43 \mathrm{mg} / \mathrm{g}$ on $\mathrm{AB}$ and $2.64 \mathrm{mg} / \mathrm{g}$ on AP for TAR. The adsorption of the two dyes increases with the initial concentration and decreases with the increase of the mass of adsorbents. The adsorption of $\mathrm{BM}$ and $\mathrm{TAR}$ on $\mathrm{AB}$ and $\mathrm{AP}$ is a fast process with an equilibrium time of 25 minutes for $A B$ and 15 and 30 minutes respectively for TAR and BM on AP. The adsorption capacity of BM and TAR decreases with increasing $\mathrm{pH}$ of the reaction medium and the maximum adsorption capacity is obtained at $\mathrm{pH}=3$. The modeling of the adsorption kinetics reveals a conformity to the pseudo-second order model for the two dyes studied on adsorbent disputes. Experimental results are better described with the Freundlich isothermal model. The thermodynamic parameters showed that the adsorption of the two dyes is favorable and endothermic.

\section{References}

[1] Mansour R., (2018). Natural dyes and pigments: Extraction and applications. Handbook of Renewable Materials for Coloration and Finishing, pp 75-102.

[2] Gautam R. K., Rawat V., Banerjee S., Sanroman M. A., Soni S., Singh S. K., Chattopadhyaya M. C., (2015b). Synthesis of bimetallic Fe-Zn nanoparticles and its application towards adsorptive removal of carcinogenic dye malachite green and Congo red in water. J. Mol. Liq., 212: 227-23.

[3] Etim U. J., Umoren S. A., Eduok U. M., (2016). Coconut coir dust as a low-cost adsorbent for the removal of cationic dye from aqueous solution. J. Saudi Chem. Soc., 20, 67-76.

[4] Najafi H., Pajootan E., Ebrahimi A., Arami M., (2016). The potential application of tomato seeds as low-cost industrial waste in the adsorption of organic dye molecules from colored effluents. Desalin. Water Treat, 57, 15026-15036.

[5] Zhao X., Liu W., Deng Y., Zhu J. Y., (2017). Low-temperature microbial and direct conversion of lignocellulosic biomass to electricity: advances and challenges. Renew. Sust. Energ. Rev., 71, 268-282. 
[6] Daud Z., Nasir N., Kadir A. A., Latiff A. A. A., Ridzuan M. B., Awang H., Halim A. A., (2018). Potential of agro wastederived adsorbent material for colour removal. Deffect Diffus Forum, 382, 292-296.

[7] Silva C. E. F., Gonçalves A. H. S., Abud A. K. S., (2016). Treatment of textile industry effluents using orange waste: a proposal to reduce color and chemical oxygen demand. Water Sci. Technol., 74, 994-1004.

[8] Saini J., Garg V. K., Gupta R. K., (2018). Removal of methylene blue from aqueous solution by $\mathrm{Fe}_{3} \mathrm{O}_{4} @ \mathrm{Ag} / \mathrm{SiO}_{2}$ nanospheres: synthesis, characterization and adsorption performance. J. Mol. Liq., 250, 413-422.

[9] Wang Y., Zhang Y., Li S., Zhong W., Wei W., (2018). Enhanced methylene blue adsorption onto activated reedderived biochar by tannic acid. J. Mol. Liq., 268, 658-666.

[10] Lagergren S. (1898). About the theory of so-called adsorption of soluble substances. Der Sogenannten adsorption geloster stoffe Kungliga Svenska Vetenska psalka de Miens Handlingar, 24: 1-39.

[11] Hameed K. S., Muthirulan P., Meenakshi S. M., (2017). Adsorption of chromotrope dye onto activated carbons obtained from the seeds of various plants: Equilibrium and kinetics studies. Arabian J. Chem., 10, S2225-S2233.

[12] Chaheb N., (2016). Adsorption of methylene blue on raw touggourt clay, master thesis, Mohamed Khider-BisKra University.

[13] Mezenner N. Y., Bensaadi Z., Lagha H., Bensmaili A., (2012). Study of the adsorption of a mixture of biorecalcitrant compounds in an aqueous medium, Larhyss journal, 11: 7-16.
[14] Akar S., Uysal R., (2010). Untreated clay with high adsorption capacity for effective removal of C. I. Acid Red 88 from aqueous solutions: Batch and dynamic flow mode Studies, Chemical Energineering journal, 162: 511- 598.

[15] Limousin G., Gaudet J. P., Charlet L., Szenknect S., Barthes V., Krimissa M., (2007). Sorption isotherms: A review on physical bases, modelling and measurement, Applied Geochemistry, 22: 249-275.

[16] Pignatello J. J., (1999). The measurement and interpretation of sorption and desorption rates for organic compounds in soil media, Advances in Agronomy, 69: 1-73.

[17] Mayeko A. K. K., Vesituluta P. N., Phanzu J. N. D., Muanda D. M. W., Bakambo G. E., Lopaka B. I., Mulangala J. M., (2012). Adsorption of quinine dihydrochloride on an inexpensive activated carbon based on sugarcane bagasse impregnated with phosphoric acid, Int. J. Biol. Chem. Sci., 6: 1337-1359.

[18] Miraboutalebi S. M., Nikouzad S. K., Peydayesh, M. Allahgholi N., Vafajoo L., Mckay G., (2017). Methylene blue adsorption via maize silk powder: Kinetic, equilibrium, thermodynamic studies and residual error analysis. Process Saf. Environ., 106, 191-202.

[19] Noll K. E., Gounaris V., Hou W. S., (1991). Adsorption theory in: Adsorption technology for air and water pollution control, CRC Press 2, 21p.

[20] Crittenden B. D., Thomas W. J., (1998). Fundamentals of adsorption equilibria in: Adsorption technology and design, Elsevier 3, 31p. 